\title{
O negro em diáspora: um fazer histórico
}

Stefane Soares Pereira ${ }^{1}$

RESUMO: Este trabalho observa a ficção das obras A mercy (2009), de Toni Morrison e Ponciá Vicêncio (2006), de Conceição Evaristo como um recontar histórico cujo objetivo é resgatar o passado para construir um presente-futuro consciente dos direitos de igualdade social. E esse processo encontra um caminho a partir da literatura contemporânea.

ABSTRACT: This text observes fiction in the works of Toni Morrison, A mercy (2009) and Conceição Evaristo, Ponciá Vicêncio (2006) as a historical re-telling whose aim is to recover the past in order to construct a conscious present-future of rights of social equality. And this process finds its way through contemporary literature.

PALAVRAS-CHAVE: Diáspora; História; Literatura feminina.

KEY-WORDS: Diaspora; History; Feminine Literature.

\section{Introdução}

O que importa para o dialético é trazer o vento da história mundial para as suas velas. Pensar para ele significa: içar as velas. O importante é o modo como elas são içadas. As palavras são as suas velas. O modo como são içadas as convertem em conceitos.

Walter Benjamin

Mas se é verdade [...] que um excesso de conhecimentos históricos prejudica o ser vivo, também é necessário entender que a vida precisa do serviço da história.

Friedrich Nietzsche

Neste trabalho veremos que a literatura da diáspora de autoria feminina vem não apenas buscando, mas rastreando, fixando o seu lugar de enunciação. Esse é o caminho encontrado para que vozes subordinadas possam libertar-se, no presente e no futuro, conscientizando aqueles que se aventuram pela leitura.

Trabalharemos com as obras A Mercy (2009), da escritora estadunidense Toni Morrison, e Ponciá Vicêncio (2006), da brasileira Conceição Evaristo. Justificamos a escolha dessas autoras: esta, para expandir e difundir o valor de sua obra no debate acadêmico nacional quanto a questões relacionadas ao negro na sociedade brasileira contemporânea; aquela pelo reconhecimento em âmbito internacional de suas narrativas sobre o negro e a escravidão e/ou pelas questões resultantes da colonização.

\footnotetext{
${ }^{1}$ Mestre em Teoria da Literatura: Estudos Literários pela Universidade Federal de Juiz de Fora. Atual doutoranda da mesma instituição. Email: stefane87@ gmail.com
} 
Tanto Evaristo como Morrison constroem uma narrativa que dialoga em termos de experiências e vivências: uma consciência da dominação imposta ao sujeito negro e um sentimento de contra-argumentar, historicamente, signos sociais.

\section{A busca pela igualdade e o escrever histórico}

Acredita-se que, com o reconhecimento político da desigualdade social, acontece também um reconhecimento da desigualdade racial. Não se sabe, porém, o grau desse tipo de conscientização. A literatura da diáspora (não apenas negra, mas judaica, chinesa, entre outras) vem com o propósito de compor as diferenças, demarcando-as no tempo, no espaço e na escritura em contraposição às ideologias culturais. Caracterizando-se pelo domínio da palavra, a literatura pode chegar a significar também a expansão da mesma, em sociedades cuja prática da leitura constitui hábito diário.

Conceição Evaristo, no artigo "Literatura negra: uma voz quilombola na literatura brasileira" (2010), afirma o papel de sua escrita na literatura brasileira, objetivando trazer novos pronunciamentos em relação à representação do corpo do negro, exprimindo sua insatisfação quanto ao lugar do negro na sociedade brasileira (como escravo, oprimido, pobre, excluído, dominado), referente às políticas de igualdade, direitos, deveres, e também oportunidades. A escritura propagada pela história ressurge na literatura como forma de resistência, em busca de um novo lugar do negro:

No Brasil, podemos encontrar, sobretudo na voz dos descendentes de africanos, uma poética que rememora a Mãe África, denuncia a condição de vida dos afro-brasileiros, e, nas últimas décadas, apresenta-se afirmando um sentimento positivo de etnicidade. Tendo sido o corpo negro, durante séculos, violado em sua integridade física, interditado em seu espaço individual e social pelo sistema escravocrata do passado e, hoje ainda por políticas segregacionistas existentes em todos, se não em quase todos, os países em que a diáspora africana se acha presente, coube aos descendentes de africanos, espalhados pelo mundo, inventar formas de resistência. Vemos, pois, a literatura buscar modos de enunciação positivos na descrição desse corpo. (EVARISTO apud PEREIRA, 2010, p. 134)

O saber certamente ocupa posição central na vida das autoras escolhidas para a composição do nosso trabalho. Evaristo e Morrison não só têm conhecimento da história do sistema escravagista nas sociedades brasileira e estadunidense, mas também representam o resultado desse processo, visto que são negras, cresceram questionando tanto o olhar destinado ao negro quanto o posicionamento (o lugar) ocupado pelos mesmos na sociedade. O estudo e o aperfeiçoamento profissional através da academia 
de Letras contribuíram para que as escritoras analisassem, por meio da literatura, a maneira como esse lugar do negro vem sendo representado e como elas próprias o criticam e o reescrevem. O conhecimento histórico permite ver, de maneira mais adequada, os caminhos e trajetórias percorridos por diversos povos. Cabe ressaltar, entretanto, a existência de privilégios de determinados grupos sobre a escrita, além de mitos. Paul Gilroy (2008) alerta para que os negros do mundo moderno mantenham a porta da tradição aberta a respeito da memória da escravidão racial, evitando seu apagamento nos dias atuais:

[...] existe o perigo de que, afora a arqueologia das sobrevivências tradicionais, a escravidão torne-se um feixe de associações negativas, que é melhor deixar para trás. A história das fazendas e usinas de açúcar supostamente oferece pouca coisa de valor quando comparada às concepções elaboradas da antiguidade africana contra as quais são desfavoravelmente comparadas. Os negros são instados quando não a esquecer a experiência escrava que surge como aberração a partir do relato de grandeza na história africana, então a substituí-la no centro de nosso pensamento por uma noção mística e impiedosamente positiva da África que é indiferente à variação intra-racial e é congelada no ponto em que os negros embarcaram nos navios que os levariam para os inimigos e horrores da Middle Passage. (GILROY, 2008, p. 355)

É dessa maneira, portanto, que Evaristo e Morrison produzem literatura sobre a diáspora negra. Como romancistas, as autoras apropriam-se do real - a história da escravidão - , construindo acontecimentos particulares. Contribuem, assim, para a memorização da história e sua importância na construção da crítica literária que examina fatos sociais. Para tal proposta, fazem uso de um olhar que pode ser descrito como o de um historiador, cujo currículo compõe-se de uma mistura entre arte, experiência e prática literária. Para Evaristo, a integração entre a arte e o conhecimento está intrinsecamente ligada ao fazer de uma "literatura negra":

Preocupações surgem quanto ao termo literatura negra, pois há a argumentação de que a arte é universal, não tem fronteiras. Sim, mas dentro dessa universalidade, há o particular, há o específico, há no caso, da literatura negra, a identidade étnica e cultural, revelando-se em momentos discursivos quando se busca uma ação afirmativa, construída pela palavra literária, e que dá um sentido positivo à etnicidade negra. (PEREIRA, 2010, p. 134)

Ao falar do negro, Evaristo articula por meio de sua escrita sobre algo específico, próximo à sua experiência pessoal, ou seja, ao apoiar-se na nomeação do ser negro, a autora define sua escritura. Zilá Bernd, na obra Introdução à literatura negra 
(1988, p. 20-22) ressalva que o termo "literatura negra" provém do desejo de nomeação dos próprios autores:

No que concerne à literatura negra, sua característica maior talvez seja aquela ligada aos procedimentos de (re)nomeação do mundo circundante. Ora, nomear equivale a tomar posse do que foi nomeado. Em certa medida a função da crítica também é a de nomear: é tornando visíveis as descobertas feitas pelos autores que os críticos as transformam em história da arte, ou melhor, as legitimam. Assim, ao referendar uma expressão reivindicada pelos autores, a crítica está atuando como instância legitimadora dessa produção literária [...] o fato de assumirem essa nomeação, conscientemente, pode ser interpretado como um sinal de que os negros estão querendo criar a si mesmos e que uma das etapas deste processo seria justamente a de particularizar sua escritura, dando-lhe feição própria [...] Assumir a condição negra e enunciar o discurso em primeira pessoa parece ser o aporte maior trazido por essa literatura, constituindo-se em um de seus marcadores estilísticos mais expressivos.

Apesar de Morrison, em A Mercy (2008), trabalhar com diversas etnias (nativos estadunidenses, negros descendentes de africanos e europeus), preocupando-se de fato com o Outro, sendo este negro ou não, usamos, neste trabalho, o termo "literatura negra" tanto para a obra de Evaristo quanto para a obra de Morrison. De fato, na citação seguinte do livro Quiet as it's kept: shame, trauma and race in the novels of Toni Morrison (2000), de J. Brooks Bouson, a autora ratifica o processo de violência sofrido, de alguma forma, por todos, e o narrador da obra que pronuncia sua experiência em primeira pessoa é uma escrava negra. Em entrevista à NPR, Morrison afirma: "Eu queria que a voz dela pudesse tocar outras vozes. Então ela é primeira pessoa, primeira pessoa e apresentadora a dar a vivacidade. Todas as outras pessoas são terceira pessoa",

Para Morrison, escrever é uma "compulsão"; é "falar profundo" dentro dela mesma, uma "extraordinária maneira de pensar e sentir" (Stepto 24, Tate 169, Watkins 45). Ela também diz que "Manter em segredo a maioria de nossos assuntos, nossa existência aqui, tem sido grotesco" (Jones and Vinson 181). Uma das preocupações centrais de Morrison é "com o sobreviver por inteiro em um mundo onde nós somos, todos nós, em alguma medida, vítimas de alguma coisa" e "em posição nenhuma para fazer algo sobre isso" (Bakerman 40). ( BOUSON, 2000, p. 2)

\footnotetext{
2 "I wanted her voice which would touch into the other voices. So she's first person, first person and presenter to give the immediacy. Everybody else is third person" (Tradução nossa).

3 "For Morrison, writing is a "compulsion"; it is "talking deep" within herself, a "extraordinary way of thinking and feeling" (Stepto 24, Tate 169, Watkins 45). She also says that "[Q]uiet as it's kept much of our business, our existence here, has been grotesque" (Jones and Vinson 181). One of Morrison central concerns is "how to survive whole in a world where we are all of us, in some measure, victims of something" and "in no position to do thing about it" (Bakerman 40 )" (Tradução nossa).
} 
Nesse sentido, podemos dizer que a escrita de Morrison surge de um interesse atual de denunciar os abusos causados pelo outro. Segundo Paul Ricoeur, na obra $A$ memória, a história e o esquecimento (2000), o “discurso da preocupação é, em primeiro lugar, um discurso centrado no presente vivo. No cerne do dispositivo da linguagem, preside o 'agora que...' a partir do qual todos os acontecimentos se deixam datar" (2010, p. 394). Mas o presente dialoga constantemente com o passado e, por vezes, esse binômio propõe um debate irresoluto. Não pressupomos como regra ser o presente a representação do passado, embora observemos a coexistência temporal da história na escrita literária. Ao discorrer sobre a condição histórica, Ricoeur usa a expressão "ser-no-tempo" para enfatizar que os sujeitos participam dos fatos ocorrentes no mundo ("ser-no-mundo"). O papel da escrita de Evaristo e Morrison assume o corpo do "historiador", o qual se volta para a reconstrução dos "atores" da história:

O historiador não tem apenas como contraponto mortos, para os quais ele constrói um túmulo escriturário; ele não se dedica apenas a ressuscitar viventes de outrora, que não existem mais, mas que existiram; ele se dedica a re-apresentar ações e paixões [...] A história visa não apenas ao vivente de outrora, na retaguarda do morto de hoje, mas ao ator da história decorrida, desde que se decida "levar a sério os próprios atores". (RICOEUR, 2010, p. 396)

O historiador se dedica a "despertar os mortos" — ou regressa para o que Ricouer (2010, p. 395) chama de "ser-para-a-morte" —, ao "re-apresentar" as "ações e paixões" da história, assim como o faz o anjo da história de Walter Benjamin, em Illuminations (1973). A história presume a memorização de acontecimentos marcantes, datados, e influentes. A literatura "re-apresenta" essa memória com novos personagens, focando, sim, em um tempo exteriorizado, uma vez que se podem encontrar indícios do tempo histórico nas narrativas. No entanto, este é concomitantemente re-construído e recriado, propositalmente no presente, refletindo sobre o mesmo, criticando-o, analisandoo, talvez explicando-o e sugerindo desdobramentos sobre a problemática que este vem carregando. Benjamin discorre sobre a imortalidade desse anjo que olha "para trás" devido à calamidade presente, no agora, em seus pés:

Seu rosto está voltado para o passado. Onde percebemos uma cadeia de acontecimentos, ele vê uma única catástrofe que segue amontoando destroços sobre destroços e os lança diante de seus pés. $\mathrm{O}$ anjo gostaria de ficar, despertar os mortos e recompor o que foi despedaçado. Mas um vendaval está soprando do Paraíso; e atingiu-o nas asas com tal violência que o anjo já não pode mais fechá-las. Esse vendaval o impele irresistivelmente para o futuro, ao qual tem as costas voltadas, enquanto a pilha de detritos diante dele vai se 
erguendo rumo ao céu. Esse vendaval é o que se chama progresso. (BENJAMIN, 1973, p. 259)

Dever-se-á compreender que a escrita de autoria feminina da diáspora negra tem por característica fundamental o questionamento das ideologias socialmente partilhadas e presentes na sociedade contemporânea. A ficção traz essas bases discursivas como um vendaval. Este convive com o anjo da história na interface do tempo e do espaço. As autoras que compõem esse trabalho pretendem reescrever, como diz Zilá Bernd, a "história da arte", questionando não apenas o momento em que vivem, como também resgatando experiências passadas. Objetiva-se utilizar as duas instâncias temporais, o passado e o presente, e com elas interagir (ferramenta fundamental para a análise do que está por vir), observando o relacionamento influente do tempo com as formas espaciais. Dessa forma, o vendaval é capaz de influir na maneira como as "velas são içadas", garantindo sua permanência conceitual ao questionar noções, como as do "progresso". Afinal, o progresso não está, necessariamente, ligado à ordem, talvez à esfera dos valores que lhe são incumbidos.

Resta-nos analisar a possibilidade de identificar as obras Ponciá Vicêncio e A Mercy como "ficcionalização" da história. Pode-se dizer que estas obras "simulam" um ponto de referência que está marcado pela história: a escravidão, presente nas sociedades contemporâneas e na memória silenciosa e silenciada de específicos grupos. A ficção é, sobretudo, a assimilação de dados históricos com referentes não reais. A narrativa, portanto, encontra-se no limiar entre a história e a ficção, pois "antes de tornar-se o objeto do conhecimento histórico, o acontecimento é objeto de narrativa" (RICOEUR, 2010, p. 251):

De um lado [...] a narrativa foi tida como um componente menor, até marginal, do conhecimento histórico; o processo da narrativa é então o do conhecimento. De outro, antes do desenvolvimento da narratologia na esfera da linguística e da semiótica, a narrativa é tida como uma forma primitiva de discurso, ao mesmo tempo muito ligada à tradição, à lenda, ao folclore e finalmente ao mito, e muito pouco elaborada para ser digna de fazer os múltiplos testes que marcam o corte epistemológico entre a história moderna e a história tradicional. Para dizer a verdade, as duas ordens de consideração andam juntas: a um conceito pobre de acontecimento corresponde um conceito pobre de narrativa. (RICOEUR, 2010, p. 251)

Pode-se dizer, portanto, que a literatura é a arte do conhecimento. Não estamos afirmando que outras formas narrativas não veiculam o conhecimento, mas, sim, assegurando a particularidade da literatura. Concordamos com Compagnon quando reflete, na obra Literatura para quê? (1950), sobre a existência de um pensamento da 
literatura (2009, p. 52). Além do conhecimento, a literatura também é a arte da experiência. Entretanto, vemos a literatura não apenas como uma narrativa dedicada à vivência alheia, mas também como o limiar de uma relação concomitantemente divergente e recíproca, um diálogo pessoal com o exterior.

A literatura deve, portanto, ser lida e estudada porque oferece um meio - alguns dirão até mesmo o único — de preservar e transmitir a experiência dos outros, aqueles que estão distantes de nós no espaço e no tempo, ou que diferem de nós por suas condições de vida [...] Não é que achemos na literatura verdades universais, nem regras gerais, nem somente exemplos límpidos. [...] A literatura, exprimindo a exceção, oferece um conhecimento diferente do conhecimento erudito, porém mais capaz de esclarecer os comportamentos e as motivações humanas. Ela pensa, mas não como a ciência ou a filosofia. Seu pensamento é heurístico (ela jamais cessa de procurar). [...] A literatura nos ensina a melhor sentir, e como nossos sentidos não tem limites, ela jamais conclui. (COMPAGNON, 2009, p. 47-51)

Dessa maneira, não podemos considerar a analogia entre a narrativa das autoras Evaristo e Morrison com a narrativa historiográfica, uma vez que esta se dedica a "reapresentar ações e paixões”. Nos dias atuais, pensar a literatura dessa forma é regressar à definição clássica de Aristóteles: a literatura como mimesis (isto é, representação/ficção), gozo e instrução. As "paixões" seriam a própria catharsis ou purificadas pela representação.

A literatura de autoria feminina traça caminhos que buscam rostos que estejam voltados na direção da obscuridade que se apresenta diante das comunidades e estejam dispostos a esclarecer os artefatos culturais envolvidos nesse processo. Artefatos que, embora influenciem no presente, espera-se não influenciarem o futuro. Dessa forma, pretende-se expor, através da narrativa, os movimentos e deslocamentos que deram origem a comunidades desiguais em termos raciais e sociais.

\section{A reconstituição histórica da mulher negra em Evaristo e Morrison}

Encontra-se em Ponciá Vicêncio, como em A Mercy, a inocência diante da realidade do negro. A ingenuidade da personagem Ponciá, porém, ao contrário de Florens, é desconfiada. Embora Ponciá compartilhe um imaginário semelhante ao de Florens, que vivencia a ilusão sob a realidade, Ponciá sonha e, ao mesmo, demonstra sua insatisfação, um conflito com a própria identidade. Essa característica da personagem expressa sua territorialidade e de que maneira o território como espaço concreto determina os símbolos de sua infância: 
Em outros tempos, havia sonhado tanto!Quando mais nova, sonhara até um outro nome para si. Não gostava daquele que lhe deram. Menina, tinha o hábito de ir à beira do rio e lá, se mirando nas águas, gritava o próprio nome: Ponciá Vicêncio! Ponciá Vicêncio! Sentia-se como se estivesse chamando outra pessoa. Não ouvia o seu nome responder dentro de si. Inventava outros. [...] Ela, inominada, tremendo de medo, temia a brincadeira, mas insistia (EVARISTO, 2006, p. 19).

Evaristo descreve em Ponciá um desconforto que na vida adulta vem a florescer.

Sabia que seu sobrenome refletia o poder do branco, representando a imagem do antigo proprietário das terras e dos negros. Entretanto, também sentia um desconforto com seu primeiro nome. A insatisfação de Ponciá tanto com o primeiro nome quanto com o segundo nome demonstra o peso da simbologia territorial, a busca por significados enraizados na espacialidade. O território da família de Ponciá é a imagem produzida da relação do homem branco com o homem negro na matéria:

O tempo passava [...]. Continuava achando o nome vazio, distante. Quando aprendeu a ler e escrever, foi pior ainda, ao descobrir o acento agudo de Ponciá. [...] sabia que o sobrenome dela tinha vindo desde antes do avô de seu avô [...]. O pai, a mãe, todos continuavam Vicêncio. Na assinatura dela, a reminiscência do poderio do senhor, de um tal coronel Vicêncio. O tempo passou deixando a marca daqueles que se fizeram donos das terras e dos homens. E Ponciá? De onde teria surgido Ponciá? Porquê? Em que memória do tempo estaria escrito o significado do nome dela? (EVARISTO, 2006, p. 29) ${ }^{4}$.

O tempo passava, as gerações mudavam e permaneciam, em geral, naquele espaço material, fixos e inertes no mesmo território de seus antepassados. Essa é a interpretação literal que fazemos do trecho supracitado. Entretanto, esse território apresenta-se em contínuo movimento, pois os indivíduos mudaram: deixaram de ser escravos e passaram a viver uma vida similar, mas não idêntica. Uma vida de sacrifícios, mas não torturas físicas. Provavelmente, embora os tormentos psicológicos não tenham enrijecido, permaneceram, criaram forma: a forma de um desgosto pela não mudança, de uma dor aflitiva resultante de um desejo de viver uma história diferente.

Os atores desse cenário do território brasileiro rural estão em constante transformação, uma transformação individual e, de alguma maneira, também dividida coletivamente pela amargura e pelos anseios. Os negros delineiam a forma do espaço territorial levando a matéria ao interior de cada um e almejando moldá-la de acordo com seus sonhos. O sonho de recomeçar e recriar os moldes espaciais. É assim que Ponciá abandona o território rural para migrar para a cidade, acreditando na mudança de vida, a fim de não repetir a história de seus familiares. Ao vivenciar a ilusão de melhoria de

\footnotetext{
${ }^{4}$ Grifo nosso.
} 
vida no centro urbano, Ponciá decide retornar às suas origens (o campo), na busca de si mesma. A escrita poética de Evaristo cria aos ouvidos de nós leitores o eco do fonema "a". A vogal tônica central repercute em nossos ouvidos como um chamado distante, vibratório de Ponciááááá. Esse eco ressoava no seu íntimo, mesmo longe daquele território "amaldiçoado" 5 pelo passado.

Em uma entrevista à revista Raça (2011), Evaristo afirma que "quando o negro tem necessidade de transitar por essa história que ficou tão lá atrás no passado, acho que isso mostra ainda uma certa falta de lugar numa sociedade que ainda nos exclui".

O retorno está intrinsecamente ligado à memória. Para Maurice Halbwachs, por meio da interação com o outro no espaço (chamado por Halbwachs de "ambiente material") surge a lembrança:

O espaço é uma realidade que dura: nossas impressões se sucedem umas às outras, nada permanece em nosso espírito e não compreenderíamos que seja possível retomar o passado se ele não estivesse conservado no ambiente material que nos circunda. É ao espaço, ao nosso espaço - o espaço que ocupamos [...] que devemos voltar nossa atenção, é nele que nosso pensamento tem de se fixar para que essa ou aquela categoria de lembranças reapareça [...] não há um grupo [...] que não tenha alguma relação com o lugar — ou seja, com uma parte do espaço - mas diremos também que isso está longe de ser o suficiente para explicar que, representando a imagem do lugar, sejamos levados a pensar em tal ação do grupo que lhe esteve associado. (HALBWACHS, 2010, p. 170-171)

Mas a memória somente se constrói porque entre o eu e o outro, na multiplicidade territorial, há a experiência individual, a pessoalidade, "em cada consciência individual as imagens e os pensamentos que resultam dos diversos ambientes que atravessamos se sucedem segundo uma ordem nova e que, neste sentido, cada um de nós tem uma história” (HALBWACHS, 2010, p. 57). Deve-se ressaltar, porém, neste trabalho, que os variados espaços, embora representem cada qual uma "ordem nova" (se considerarmos as referências temporais), são congruentes.

O retorno não é possível materialmente para Florens, em A Mercy. Florens somente retorna ao encontro da mãe por meio de sua memória. Sabe-se o contexto em que decorre a narrativa de A Mercy pela voz de uma escrava indígena, Lina. Lina, assim como a mãe de Florens, costumava alertar a personagem para a realidade dos nãobrancos e escravos, no século XVII, nos Estados Unidos. Nesse período, a sociedade estadunidense está em formação, principiando-se o sistema escravagista. Na citação

\footnotetext{
${ }^{5}$ Utilizamos esse termo porque abandono territorial de Ponciá foi, na realidade, uma fuga, um pavor de repetir a história de seus antepassados.
} 
abaixo, vemos claramente a separação de dois mundos - o dos escravos e o da aristocracia. A fala de Lina aponta a impossibilidade de fusão desses dois mundos:

O começo começa com os sapatos. Quando criança eu não suporto ficar descalça e sempre peço por sapatos, os sapatos de qualquer um, mesmo nos dias mais quentes. "Minha mãe", a "minha mãe", franze a testa, nervosa para o que ela chama de minhas manias de donzela. Somente mulheres ruins usam salto alto. Sou perigosa, ela diz, e rebelde, mas ela cede e me deixa usar os sapatos velhos da casa da Senhora. [...] O resultado disso, Lina diz, é que meus pés são inúteis, serão sempre macios demais para a vida e nunca terão as solas fortes, mais grossas que o couro, que a vida exige. Lina está certa. Florens, ela diz, estamos em 1690. Quem mais hoje em dia tem mãos de escrava e pés de dama portuguesa? ${ }^{7}$ (MORRISON, 2009, p. 2) ${ }^{8}$

Nesse recordar o passado, pode-se observar que a insistência da personagem para com o uso dos sapatos, em verdade, expressa sua aflição para com o contato com a terra ou mesmo com o chão, no interior da mansão do fazendeiro D’Ortega, que a mantém como escrava. O sapato representa um objeto cuja função é não apenas proteger os pés das mulheres de poder, mas, sobretudo revelar o charme e o encanto daquele que pode usufruir desse bem material. A mãe de Florens e Lina desvendam o significado alegórico desse objeto a fim de tentar mostrar a distância da mulher negra para com essa propriedade, bem como a simbologia que existe por detrás dos sapatos.

O negro, no período escravagista, é um objeto mercantil, e o território, um conjunto de mercadorias, pois no século XVII nos Estados Unidos seu valor material é realçado: é o Novo Mundo (o mundo de novos recursos). Vejamos, portanto, o valor da escrava negra Florens nesse contexto.

É relevante ressaltar que a personagem Florens não foi comprada pelo fazendeiro Jacob Vaark. Este, em uma viagem a negócios, ao tentar negociar a dívida do personagem D’Ortega - que há um mês havia perdido um terço da carga de escravos após seu navio ter ancorado uma milha náutica da costa —, recebeu como oferta um escravo, como parte do pagamento do débito. D’Ortega oferece o irmão, ainda bebê de Florens, mas a mãe de Florens oferece a filha:

\footnotetext{
${ }^{6}$ Escolhemos utilizar as aspas como forma de destacar a interferência linguística usada por Morrison a partir da língua portuguesa e da língua espanhola.

${ }^{7}$ Grifo nosso.

8 "The beginning begins with the shoes. When a child I am never able to abide being barefoot and always beg for shoes, anybody's shoes, even on the hottest days. My mother, a minha mãe, is frowning, is angry at what she says are my prettify ways. Only bad women wear high heels. I am dangerous, she says, and wild but she relents and lets me wear the throwaway shoes from Senhora's house, pointy-toe, one raised heel broke, the other worn and a buckle on top. As a result, Lina says, my feet are useless, will always be too tender for life and never have the strong soles, tougher than leather, that life requires. Lina is correct. Florens, she says, it's 1690. Who else these days has the hands of a slave and the feet of a Portuguese lady? "(Tradução nossa).
} 
Eu olhando, "minha mãe" escutando, o bebê dela no quadril. O Senhor [D’Ortega] não vai pagar a quantia toda que deve para o patrão [Vaark]. O patrão dizendo que aceita então a mulher e a menina, não o bebê menino, e a dívida acaba. A "minha mãe" implora que não. $O$ bebê ainda é de peito. Leve a menina, ela diz, minha filha, ela diz. Eu. Eu. (MORRISON, 2009, p. 5) ${ }^{9}$

Essa narrativa exemplifica claramente o posicionamento do negro como objeto, mercadoria. O objeto Florens é forçadamente movimentado em direção à fazenda de Vaark. A recepção dessa criança negra em um novo território tem por base sóciosimbólica o mesmo acolhimento oferecido no território anteriormente habitado pela personagem. Esse processo de igualdade relacional, embora pareça reafirmar a funcionalidade estática do território, na realidade, confirma as instabilidades das ações sociais realizadas no espaço. A sociedade modula o espaço territorial ao agir sobre os "objetos".

Enquanto a mobilidade de Florens é controlada, o fluxo de Ponciá constitui-se por uma fusão da autonomia e da contingência. Ponciá é uma mulher negra cuja travessia é espontânea, livre para o ir e vir, está no século XIX, em período pósabolicionista, Florens, uma escrava negra submissa ao controle do branco, está no século XVII. Pode-se dizer que ambas estão submetidas às mediações espaciais do poder, cada qual em seu tempo, tanto num nível mais concreto e material quanto num nível mais simbólico e cultural.

Há uma relevante diferença entre ouvir dizer e vivenciar um fato: como Ponciá não viveu o poder material e simbólico que envolve os negros habitantes de cidades, não tem consciência disso. Pensar que sua tentativa de mudar de vida fracassaria seria aceitar o domínio material e, principalmente, simbólico imposto pelo território rural. Em outras palavras, enquanto Ponciá rebela-se contra a impossibilidade de melhoria de vida e crescimento do negro, Florens, ainda menina, vivencia o comércio de pessoas, a negociação de seu próprio eu. Essa experiência, a nosso ver, seria suficiente para que a personagem ao menos suspeitasse de uma conjuntura social injustamente dominadora e poderosa. Entretanto, Florens julga o comportamento da mãe, culpando-a por sua desterritorialização e confortando-se com a invisibilidade social.

\footnotetext{
9 "Me watching, my mother listening, her baby boy on her hip. Senhor is not paying the whole amount He owes to Sir. Sir saying he will take instead the woman and the girl, not the baby boy and the debt is gone. A minha mãe begs no. Her baby boy is still at her breast. Take the girl, she says, my daughter, she says. Me. Me" (Tradução nossa).
} 
Evaristo explicita na obra, através do silêncio de Ponciá e da sua incapacidade em confessar para a mãe seus planos, sua agonia, o desejo da personagem de não repetir a história dos seus:

Por que uma ida tão repentina, como um gesto de quase fuga? Ponciá não conseguiu explicar que sua urgência nascia do medo de não conseguir partir. Do medo de recuar, do desespero por não querer ficar ali repetindo a história dos seus. Agora na cidade, sozinha, para onde deveria ir? O que deveria fazer? Já perdera muito tempo contemplando cada detalhe da fé externada naquela casa de Deus. Escutou o barulho de portas pesadas se movimentando. Era o sacristão que fechava a igreja. Confusa, saiu sem saber que rumo tomar. (EVARISTO, 2006, p. 38-39)

Ponciá busca escapar do símbolo instituído (melhor dizendo, construído) no território rural, a ideia de que os negros vivem dentro de um padrão igualitário e imutável. A rejeição de Ponciá evidencia a característica móvel do território, na medida em que sua vontade de abandonar aquele território não é um fato isolado da personagem, senão também de outros sujeitos atuantes no processo de movimentação territorial. Ao migrarem para a cidade, esses negros e negras ratificam a mudança no sentido relacional do território: o território traduz-se pela ação, pelo movimento repetitivo de acontecimentos, sobre o qual é exercido o controle do espaço.

Em entrevista postada no sítio YouTube intitulada "Toni Morrison talks about her motivation for writing" (2011), a autora afirma que as mulheres negras são representadas em livros por escritores negros e brancos como empregadas, cozinheiras e outros, mas as crianças "eram sempre menos". ${ }^{10}$ Além disso, a escritora questiona as construções elaboradas por escritores negros sobre os negros, em meados do século XX. O que motiva a escrita de Morrison, portanto, é o desejo de resgatar uma verdade do negro estadunidense “abafada". Nessa entrevista, Morrison expõe seu sentimento de mal-estar para com a publicação de algumas obras nos Estados Unidos.

Em entrevista ao Boletín PPCOR, n. 31 (2011), Conceição Evaristo faz uma crítica à representação do negro nas obras de literatura brasileira. Para a autora, não somente os textos produzidos no passado, também os textos contemporâneos proliferam estereótipos que contribuem com a reprodução negativa da imagem do negro. A autora também enfatiza, de maneira bastante consciente, que essas re-produções são construções socioculturais, isto é, são criações exclusivamente difundidas por grupos dominantes e compartilhadas por grupos menores: "A literatura brasileira segue ao longo do tempo difundindo estereótipos de negros em várias obras. Textos escritos no

\footnotetext{
10 "the children were always less" (Tradução nossa).
} 
passado e na contemporaneidade [...] reatualizam estereótipos tais como: o do negro Pai-João, o da Mãe-Preta, o do negro preguiçoso".

Pode-se afirmar como sendo a grande motivação para a escrita de Evaristo e Morrison o questionamento e a insatisfação com a representação fictícia e certamente real do negro nas sociedades habitadas pelas autoras. Vemos em suas narrativas a reprodução de comportamentos ideológicos de indivíduos dominantes, negros e nãonegros: em Ponciá Vicêncio, por exemplo, vemos no campo, a crença na não legitimidade do povo negro, na medida em que Ponciá confirma a falta desse poder também na cidade, ao tentar subverter o poder simbólico "determinado" socialmente, mesmo fracassando; em A Mercy, Morrison constrói uma personagem, Florens, que sofre a imposição do poder de agentes sociais brancos.

\section{Conclusão}

De um lado a escravidão revela a fragilidade do ser humano, o controle da mobilidade, a submissão do negro para com o branco, demonstra a dependência do negro ao sistema político-econômico vigente. De outro, a sociedade escravocrata, assim como pós-abolicionista, possibilita uma liberdade comedida através da fuga do espaço material (como pretendia Florens, ao reencontrar seu amado, ou como perfez Ponciá, ao migrar do campo para a cidade), e simultaneamente do contexto espacial de insatisfação presente no interior das personagens como causalidade do exterior (Ponciá, em ato de desespero, foge de si mesma, da herança deixada por seu avô; mergulha na sua doença mental, integrante de múltiplas faces, múltiplas experiências subjugadas ao ser negro).

A cidade é para Ponciá uma forma de se reterritorializar, buscando novos espaços para o negro, soprando ainda mais para trás o vento e as histórias conhecidas dos negros para um passado bem distante. Ponciá almeja uma realização que, na realidade, não se funda como apenas sua, mas como a negação do fracasso de todo uma coletividade negra: aqueles que se fixam no conformismo de permanecer naquele lugar emoldurado na rachadura do espelho da escravidão, conglomerado pelas lembranças dolorosas do passado e presentes em uma tradição memorial involuntária. Florens vê na escrava indígena Lina o seu mundo, apesar de um ser não poder substituir outro ser, Lina incumbiu-se das funções de mãe aconselhadora.

A literatura feminina de Evaristo e Morrison favorece o diálogo, o rever os signos e os símbolos que transcendem as fronteiras nacionais. A sociedade necessita do problema para autoavaliar-se, abrindo os olhos à invisibilidade imposta na contemporaneidade à origem do negro, as formas de fixar o espaço e também o tempo 
no passado. O passado deve ser dialogado com o presente, as circunstâncias trazidas pelo "anjo da história". Nós somos da América, nascemos neste território, convivemos neste espaço, e este é o nosso lugar.

\section{Referências Bibliográficas}

BENJAMIN, Walter. Illuminations. Londres: Fontana, 1973.

BERND, Zilá. Introdução à literatura negra. São Paulo: Brasiliense, 1988.

BOUSON, J. Brooks. Quiet as it's kept: shame, trauma, and race in the novels of Toni Morrison. Albany: State University of New York Press, 2000.

COMPAGNON, Antoine. Literatura para quê? Trad. Laura Taddei Brandini. Belo Horizonte: Editora UFMG, 2009.

EVARISTO, Conceição. Entrevista. In.: Boletín PPCOR. n. 31. LPP, Laboratorio de Políticas Públicas, UERJ: Brasil, abril/maio. 2007. Disponível em: <http://www.lpp-uerj.net/olped/acoesafirmativas/boletim/31/entrevista.htm>. Acesso em: 4 out. 2011.

EVARISTO, Conceição. Exclusivo Online Entrevista. Disponível em: $<$ http://racabrasil.uol.com.br/cultura-gente/96/artigo15673-3.asp>. Acesso em: 4 out. 2011.

EVARISTO, Conceição. Literatura negra: uma voz quilombola na literatura brasileira. In.: PEREIRA, Edimilson de Almeida (org.). Um tigre na floresta de signos: estudos sobre poesia e demandas sociais no Brasil. Belo Horizonte: Mazza Edições, 2010.

EVARISTO, Conceição. Ponciá Vicêncio. Belo Horizonte: Mazza Edições, 2006.

GILROY, Paul. O Atlântico negro: modernidade e dupla consciência. Trad. Cid Knipel Moreira. Rio de Janeiro: Editora 34, 2008.

HALBWACHS, Maurice. A memória coletiva. Trad. Beatriz Sidou. São Paulo: Centauro, 2011.

MORRISON, Toni. A mercy. London: Vintage, 2009.

MORRISON, Toni. Toni Morrison interview to NPR, by Lynn Neary. Disponível em: $<\mathrm{http} / / / \mathrm{www} . n$ pr.org/player/v2/mediaPlayer.html?action=1\&t=1\&islist=false $\& \mathrm{id}=9$ 5961382\&m=96095502>. Acesso em: 10 out. 2011. 
MORRISON, Toni. Toni Morrison talks about her motivation for writing. Disponível em: 〈http://www.youtube.com/watch?v=_8Zgu2hrs2k>. Acesso em: 6 ago. 2011.

RICOUER, Paul. A memória, a história, o esquecimento. Campinas: Editora da Unicamp, 2010. 